\title{
ACUTE PORPHYRIA WITH EPILEPTIFORM CONVULSIONS
}

\author{
By I. M. P. SMeEd, M.A., M.B., B.Chir. \\ Formerly House Physician, North Middlesex Hospital
}

A number of cases of acute porphyria have been reported in the literature in the past few years and it is becoming increasingly clear that the disease is not as rare in this country as was previously thought, even in patients with no Scandinavian ancestry. The following case is of interest because several major epileptiform fits occurred without the development of other manifestations in the nervous system.

\section{Case Report}

A married woman, aged 23 years, was admitted to the North Middlesex Hospital on October 7, I953, with a history of vague, poorly-localized attacks of abdominal pain over the previous three months. For one week before admission she had experienced far more severe pain situated in the right upper quadrant of the abdomen, associated with vomiting and marked constipation. The latter had been relieved by enemata but this made no difference to the pain. She had noticed nothing abnormal about her urine before, during or after these attacks.

Phenobarbitone had been administered intermittently from September 28 to the time she was admitted and four capsules of amylobarbitone sodium ( 3 grains each) had been taken on the four days prior to admission.

The patient had been quite well in the past, apart from an appendicectomy ten years previously. No record could be obtained of the pathology of the appendix. There was no relevant family history. On direct questioning, her husband stated that he had noticed some slight personality change over the previous three months: whereas she had been gay, vivacious and even-tempered she was now quiet and easily upset by small mishaps.

On the day of admission to hospital she had a major epileptiform attack. On arrival at the hospital she was mentally confused and, while being examined, had the typical tonic and clonic stages of an epileptiform fit without incontinence. Directly after the fit her corneal reflexes were absent and all other reflexes diminished. She was given 3 grains of phenobarbitone by injection. The reflexes returned to normal within a few minutes.

Examination revealed that the exposed parts of the body were sunburned from a recent holiday, but there was no other skin lesion. There was slight generalized abdominal tenderness but no rigidity, muscle spasm nor rebound tenderness. Scybalae were felt as high up the colon as the caecum. Her blood pressure was I54/1 14. She had enlarged and slightly tender glands in both groins and a brown-stained mucus discharge was found on vaginal examination. There was no abnormality detected in the nervous system and the urine was a normal colour containing no albumen, reducing substances nor ketones.

During the rest of that day and the following night she had four more fits, making a total of six in all. On the next day it was reported that the patient had passed red urine which became darker on standing. This port-wine coloured urine gave a strongly positive reaction to Ehrlich's aldehyde reagent.

All barbiturates were omitted after porphyrins were found in the urine and the fits ceased and did not recur. Her mental state rapidly returned to normal. The constipation and abdominal pain took much longer to clear and, for three weeks, she continued to have very severe attacks of pain, relieved by pethidine or Physeptone. In between attacks of pain she was cheerful and active.

\section{Investigations}

Chemical tests of the urine showed the presence of uroporphyrin and porphobilinogen. Twentyfour-hour specimens were examined by Professor C. Rimington who reported that the highest level of porphyrins excreted was $9.33 \mathrm{mg}$. per day. Pharmacological testing of urine and plasma showed no effect on the blood pressure nor respirations of a cat. The urines from the only near blood relatives of the patient, her mother, brother and grandfather, showed no abnormality 
of porphyrin or porphobilinogen excretion. Examination of the blood revealed: $\mathrm{Hb}$. I2.I g. per cent. ; reticulocyte count less than I per cent.; Wassermann and Kahn reactions negative; serum sodium $280 \mathrm{mg}$. per cent., or $122 \mathrm{~m}$.eq. per litre; serum alkaline phosphatase 5.5 King-Armstrong units; Thymol turbidity 3.0 units; total plasma proteins $6.05 \mathrm{~g}$. per cent.; albumen $4.35 \mathrm{~g}$. per cent. and globulin $1.7 \mathrm{~g}$. per cent.

The report on the electroencephalogram taken on November 17 was as follows:" The E.E.G. is mildly abnormal. A low medium voltage alpharhythm is dominant but tended to be unstable in frequency and very mild dysrhythmia is seen at times. There is no significant asymmetry nor focal abnormality, nor disturbance on overbreathing. This record is non-specific and only just outside normal limits, but compatible with the epileptic diathesis. The fits may well have occurred in response to physiological stresses while in hospital.'

\section{Progress}

After three and a half weeks in hospital the patient was discharged home symptomless, although still passing some porphyrins in the urine. Her basal blood pressure was 146/94. Since discharge she has continued to have attacks of diffuse abdominal pain, extreme constipation and vomiting, twice necessitating admission to hospital. During these attacks the urine has always been dark red. The pain, which usually seemed to be worse before menstruation, was relieved when the period started. On one occasion she experienced sub-sternal pain relieved by amyl nitrate. No further fits have occurred and there have been no abnormal neurological findings, although on one occasion it was reported that her right arm was twitching.

\section{Discussion}

It has been pointed out by Gray, Rimington and Thomson (1948) that the so-called acute porphyrias are really chronic metabolic disorders subject to severe acute episodes. The patients often experience long asymptomatic phases during which the disease can only be detected by special tests carried out on the excreta. Certainly in this case, although we have no record of porphyrins passed before the symptoms began, porphyrins were still present in the urine after discharge from hospital, although the patient was symptomfree. The acute manifestations of the disease appear either spontaneously or as a result of the administration of certain drugs (Petrie, I948). In the absence of any effective specific treatment, it is important that all possible precipitating drugs should be considered. Drugs which are impli- cated are sulphonamides (Dudley Hart and Collard, I950), sulphonal, methyl sulphonal (Hill, 1952), barbiturates, alcohol and arsenicals (Dobriner and Rhoads, 1940). Of these, barbiturates have been cited most often. Abrahams, Gavey and Maclagan (1947) report a case of a woman with the disease who was given a course of sulphonamides with Soneryl nightly for some time and later Nembutal. After this she had a fit and developed muscular weakness. It was thought that this may well have been due to the barbiturates. Discombe and D'Silva (1945) had a male patient, aged 19, with porphyria who had six relapses during a period of three years, in some of which there were fits. During two of the relapses he was given phenobarbitone for periods of several weeks, but the drug did not seem to affect the disease adversely. In the case reported here no barbiturates had been given prior to the onset of abdominal pain, but the convulsions occurred after phenobarbitone and amylobarbitone sodium had been taken and ceased when all barbiturates were stopped, thus some association with the administration of barbiturates seemed indicated. Waldenström (1940) advised the restriction of sedative drugs to opiates and this patient has been warned to take no barbiturates and no drug of which she is not sure of the nature. The disease followed the typical three phases described by Petrie (1948). Firstly, there was a prodromal phase with some mental symptoms. A marked loss of weight is often a feature at this stage but this patient did not report any change. Secondly, the phase of abdominal symptoms occurred. In this case, as often happens, abdominal pain was so severe that the patient was sent to hospital as an acute abdominal emergency. Dark urine usually appears during or before this stage and there is often some hypertension. The third phase consists of symptoms and signs referable to the central nervous system. It is interesting to note that convulsions alone occurred and the patient presented none of the other more common manifestations of nervous system involvement, namely, muscular weakness and paralysis, wasting, absent reflexes or altered sensations.

\section{Summary}

A case of acute porphyria occurring in a young and previously healthy woman is reported.

In addition to abdominal symptoms and dark urine the patient presented with major epileptiform fits following the administration of barbiturates, but no other neurological symptoms or signs. No further fits occurred after barbiturates were stopped. 
I am indebted to Dr. Norman Whittaker, Physician to the North Middlesex Hospital, for much valuable help and guidance and for permission to publish this case. I also wish to thank Professor Rimington and Dr. A. Goldberg for the porphyrin estimations and pharmacological tests.
BIBLIOGRAPHY

GRAY, C. H., RIMINGTON, C., and THOMSON, S. (1948), Quart. F. Med., n.s., 41, 123 .

PETRIE, E. (1948), Brit. med. $¥$., i, 926

DUDLEY HART, F., and COLLLARD, P. (1950), Ibid., i, 278. HILL, R. (1952), Ibid., ii, 698 .

DOBRINER, K., and RHOADS, C. P. (1940), Physiol. Rev., 20, 416.

ABRAHAMS, A., GAVEY, C. J., and MACLAGAN, W. F. (1947), Brit. med. F., ii, 327.

DISCOMBE, G., and D'SILVA, J. L. (1945), Ibid., ii, $49 \mathrm{r}$.

WALDENSTRÓM, J. (1940), Svenska LäkT., 37, 1537 .

\section{CARDIAC DISEASE}

(Postgraduate Medical Journal)

Price 3s. 10d. post free

INTRODUCTION

Walter Somerville, M.D., M.R.C.P.

ANGIOGRAPHY

J. Norman Pattinson, M.B., B.Chir., D.M.R.D.,

F.F.R.

BEDSIDE DIAGNOSIS OF CONGENITAL HEART DISEASE

Walter Somerville, M.D., M.R.C.P.

SURGICAL TREATMENT OF CONGENITAL HEART DISEASE

W. P. Cleland, M.R.C.P., F.R.C.S.

PREGNANCY AND RHEUMATIC HEART DISEASE

Samuel Oram, M.D., F.R.C.P.
DRUG TREATMENT OF HYPERTENSION

E. G. McQueen, M.B., M.R.C.P., and F. H.

Smirk, M.D., F.R.C.P.

TREATMENT OF BACTERIAL ENDOCARDITIS

Ian G. W. Hill, C.B.E., T.D., F.R.C.P.E., M.R.C.P., F.R.S.E.

THE MANAGEMENT OF COR PULMONALE J. F. Goodwin, M.D., M.R.C.P.

THE CARDIAC RISK IN ANAESTHESIA AND SURGERY

Graham W. Hayward, M.D., F.R.C.P.

Published by

THE FELLOWSHIP OF POSTGRADUATE MEDICINE 60, Portland Place, London, W.1

\section{HOW TO GET THERE}

An Address Book for the Medical profession, showing how to reach the various Colleges, Societies,. Institutes and Hospitals in or near London

New (Fourth) Edition: 1954

Published by the

Price 2s. 6d. (2s. 10d., post free)

FELLOWSHIP OF POSTGRADUATE MEDICINE

60 Portland Place, London, W.I 